\title{
An Efficient Power Control Technique for High- Frequency Resonant Inverter in Induction Heating System
}

\author{
Anand Kumar \\ Department of Electrical Engineering \\ Indian Institute of Technology \\ (Indian School of Mines) \\ Dhanbad, India \\ anand.2016dr0084@ee.ism.ac.in
}

\author{
Debayan Sarkar \\ Department of Electrical Engineering \\ Indian Institute of Technology \\ (Indian School of Mines) \\ Dhanbad, India \\ debayan.17dr000423@ee.ism.ac.in
}

\author{
Pradip Kumar Sadhu \\ Department of Electrical Engineering \\ Indian Institute of Technology \\ (Indian School of Mines) \\ Dhanbad, India \\ pradip@iitism.ac.in
}

\begin{abstract}
An efficacious and reliable power control technique has been developed which can be used to regulate the output power of a high-frequency full bridge series resonant inverter (HF-FBSRI) in an induction heating (IH) system. In this paper, a modified buck-boost converter is presented to control the DC link/bus voltage which maintains the IH system under resonant mode and optimizes the performance of the IH system. Controlled DC link/bus voltage has been applied to this HFFBSRI to control the average output power in the IH system. Using this aimed control technique, a wide range of output powers has been controlled and consistent performance of the IH system has been achieved. ZVS switching technique has been used to reduce the switching losses. Varying average power has been obtained at different duty cycles ranging from 0.2 to 0.8 with variable DC link voltage and it has been corroborated using PSIM environment for an IH system rated at $5500 \mathrm{~W}$.
\end{abstract}

Keywords-induction heating (IH) system; DC link voltage; duty cycle; FBSRI; series resonance

\section{INTRODUCTION}

Today's era reveals that the uses of induction heating $(\mathrm{IH})$ technology are increasing in industrial and domestic applications [1]. The benefits of using this technology are its high efficiency, less heating time, accurate heating pattern, safety and cost-effectiveness. Due to these unique merits, IH technology became one of the most promising methods to attain high heating performance for development in the field of high frequency (HF) inverter and its control technique [2]. IH technology can be defined as an electrical and contactless process in which workpiece/object is heated with the help of eddy current, generated by HF alternating flux/current [3]. Actually this HF alternating flux links with the workpiece and generates eddy current. Due to this eddy current, the workpiece placed inside the IH coil gets heated by the Joule principle. Generally, to generate HF current, an HF resonant inverter is used like the full bridge series resonant inverter (FBSRI) [4-5], half bridge-SRI [6], single switch topology [7], class -D [13] and so on. The demerit of resonant converters is the occurence of switching and power losses across semiconductor switches.
Zero voltage switching (ZVS) and zero current switching (ZCS) techniques are used to mitigate these losses [8]. In the current work, FBSRI has been applied with ZVS condition.

Apart from that, various power control techniques have been developed for resonant converter topologies [2]. In the resonant inverter, output power could be varied in two ways. One is by employing variable DC link voltage to the resonant inverter and another is by manipulating the time period of pulses. Out of these two techniques, pulse width modulation (PWM) technique is employed for manipulating output power. Some of the control techniques for a resonant inverter used for IH applications are: Frequency modulation technique [9], phase shift [10], pulse density modulation $[11,16]$, asymmetrical duty cycle [12] and square wave [12]. These methods are not able to maintain the IH system under resonant mode. Due to this, the performance of the IH system decreases and switching losses become more significant [12]. It has been seen in frequency modulation technique that while varying frequency the current and power through resonant tank diminish. Regarding the elimination of the aforementioned disadvantages, variable DC link voltage method is proposed in this work which has been done by a modified buck-boost dc-dc converter. In this paper, controlled output power has been achieved using modified buck boost dc-dc converter. The main advantage of DC-link voltage control technique through a dcdc converter is that, it protects from the electromagnetic disruptions at the input side of the IH system. This electromagnetic disruption is generated through a high frequency component (i.e. generated at the output side) which tries to superimpose on the input side. In this paper, additionally $L_{s}$ and $C_{s}$ have been used to eliminate this $\mathrm{HF}$ component in the input side of FBSRI. This proposed control technique can be applied in both industrial and domestic $\mathrm{IH}$ applications.

\section{PROPOSED CLASSICAL IH SYSTEM BASED ON MODIFIED BUCK BOOST CONVERTER}

The block diagram of the proposed classical IH system is shown in Figure 1. In this Figure, AC supply $(230 \mathrm{~V}, 50 \mathrm{~Hz}$ as 
per Indian standards) has been applied to the full bridge diode rectifier which converts alternating current (AC) to direct current (DC) with ripple content. After rectification, filter inductor $\left(L_{f}\right)$ and capacitor $\left(C_{f}\right)$ have been used for mitigating the ripple content in DC voltage. Later, this pure DC supply has been applied to the modified buck-boost dc-dc converter which is used to regulate DC-link voltage $\left(V_{d c l}\right)$. Now this variable DC-link voltage has been applied to a full bridge series resonant inverter (FBSRI) through a filter composed of $L_{s}$ and $C_{s}$ that eliminates high frequency components [4]. This FBSRI generates HF AC current which flows through the IH coil. Due to this, HF alternating flux generated across the coil, links with the metallic object and thus creates eddy current inside the object which is to be heated. Due to Joule's law of heating effect, the metallic object that is placed inside the IH coil gets gradually heated.

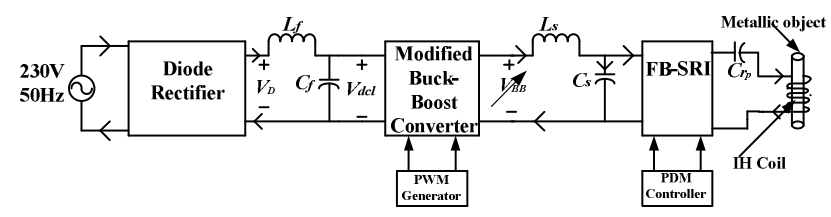

Fig. 1. Block diagram of the proposed HF induction heating system

In this paper, the heat intensity in the object is being controlled by controlling the output power of FBSRI. This has been done through the modified buck boost converter topology which controls the DC link voltage that is finally applied to the FBSRI as shown in Figure 1. The circuit configuration of modifed buck boost converter is shown in Figure 2, where $L_{b b}$ and $C_{b b}$ are the buck boost inductor and capacitor respectively. Unlike the conventional buck boost converter, the modified buck boost converter allows both input and output voltage to be of the same polarity. Switches M1 and M2 are turned ON and OFF simultaneously. When both switches are turned ON, $L_{b b}$ stores the energy and when the switches are turned OFF, $L_{b b}$ supplies energy to the load through a path incorporating both diodes, D1 and D2.

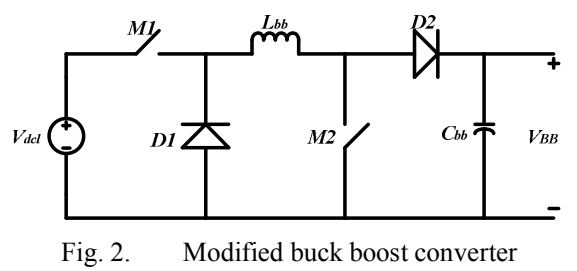

$L_{b b}$ and $C_{b b}$ have been evaluated by (1)-(2):

$$
\begin{aligned}
& L_{b b}=\frac{V_{d c l}(1-D)}{\Delta i_{L} f_{s}} \\
& C_{b b}=\frac{I_{o} D}{\Delta V_{o} f_{s}}
\end{aligned}
$$

where, $V_{d c l}$ is the DC link voltage, $D$ is the duty cycle, $\Delta i_{L}$ and $\Delta V_{o}$ are the changes in current and voltage respectively and $f_{s}$ is the switching frequency of the modified buck boost converter. The controlled output of the modified buck boost converter is fed to FBSRI. The circuit configuration for FBSRI is shown in Figure 3 [17-18]. An FBSRI generally consists of four HF semiconductor switches (i.e. MOSFETs, GTO, IGBTs) with an anti-parallel diode. Due to the switching of two switches at the same time in one leg, a quasi-square waveform is generated. Commonly, MOSFETs and IGBTs are the first choices for the resonant inverter in IH applications. In FBSRI, the IH coil and its load have been modeled as a series combination of $R_{e q}$ and $L_{e q}$ [14-15]. $C_{e q}$ is the resonating capacitor connected in series to create series resonance condition for analyzing the electrical behavior of the practical IH system. Generally, resonant inverter operates at the resonant frequency $f_{r}$. But in practical cases, switching frequency $f_{s}$ of the FBSRI must be greater or less than resonant frequency $f_{r}$ to reduce switching losses. In this work, FBSRI has been incorporated with ZVS condition.

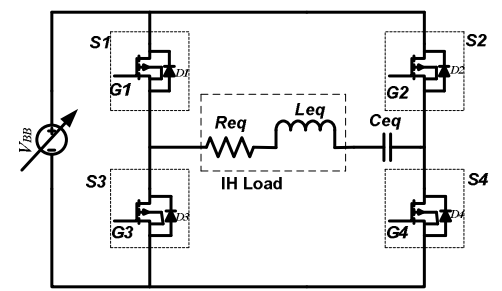

Fig. 3. Circuit configuration of FBSRI

\section{A. Mathematical Analysis of the Proposed Control Technique}

In this part, a brief description of the proposed power control technique has been presented. From Figure 1 it can be seen that the buck boost converter has been connected to control the output power of FBSRI. The proposed power control technique has been validated by the use of the following mathematical equations. Let $V_{D}$ is the average DC output voltage of bridge rectifier, $V_{d c l}$ is the average DC link voltage, and $D$ is the duty cycle. So:

$$
V_{D}=\frac{2 V_{m}}{\pi}
$$

where $V_{m}$ is the maximum input voltage and

$$
V_{d c l}=V_{D}(1-\cos \omega t)=\frac{2 V_{m}}{\pi}(1-\cos \omega t)
$$

Now the output voltage of the buck boost converter i.e. $V_{B B}$ can be written as:

$$
V_{B B}=V_{d c l} \frac{D}{1-D}=\frac{2 V_{m}}{\pi}(1-\cos \omega t) \times \frac{D}{1-D}
$$

Equation (5) reveals that $V_{B B}$ can be controlled by varying duty cycle. Let $V_{o}$ be the output voltage of FBSRI and its first harmonic amplitude can be defined as:

$$
\begin{aligned}
& V_{1}=\frac{4 V_{B B}}{\pi} \cos \alpha \\
& |Z(j \omega)|=\left|R_{e q}+j \omega L_{e q}+\frac{1}{j \omega C_{e q}}\right|=\frac{R_{e q}}{\cos \phi}
\end{aligned}
$$


where $\phi$ is the phase angle between voltage and current while the proposed FBSRI operates at resonant frequency $\left(f_{r}\right)$. Due to this, voltage and current will be in the same phase. Owing to this $\phi=\alpha$ is assumed for further analysis.

$$
\therefore|Z(j \omega)|=\frac{R_{e q}}{\cos \alpha}
$$

Fundamental output current, $I_{1}$ and output power of FBSRI can be expressed as:

$$
\begin{aligned}
& I_{1}=\frac{V_{1}}{Z(j \omega)}=\frac{4 V_{B B}}{\pi R_{e q}} \cos ^{2} \alpha \\
& P=\left(\frac{I_{1}}{\sqrt{2}}\right)^{2} R_{e q}=\frac{16 V_{B B}}{2 \pi^{2} R_{e q}^{2}} R_{e q} \cos ^{4} \alpha=\frac{8 V_{B B}}{\pi^{2} R_{e q}} \cos ^{4} \alpha
\end{aligned}
$$

From (10) it can be concluded that output power can be controlled by varying buck boost output voltage $V_{B B}$.

\section{IH LOAD ELECTRICAL MODELING AND FREQUENCY RESPONSE ANALYSIS}

\section{A. Electrical Modeling of IH Load}

To analyze the electrical behavior of the classical IH system, the electrical modeling of $\mathrm{IH}$ load is needed. The electrical modeling of $\mathrm{IH}$ load can be explained with the help of a transformer equivalent circuit representation because $\mathrm{IH}$ system works on the principle of electromagnetic induction between the IH coil (which acts as a primary winding) and the load (which will act as a secondary winding) [19-20]. The electrical equivalent circuit of IH load is shown in Figure 4. In this figure, $L_{P}$ and $L_{S}$ are the self-inductances in the primary and secondary side respectively. $M$ is the mutual inductance of transformer equivalent circuit. $R_{L}$ is the resistance of the object to be heated which is placed inside the IH coil.

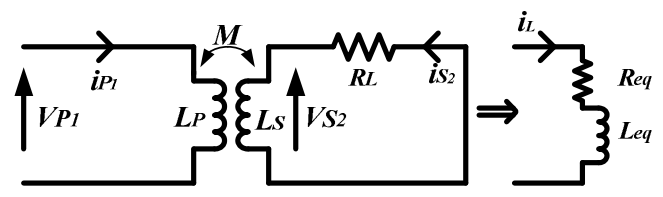

Fig. 4. Transformer model/equivalent circuit of IH load

$R_{e q}$ and $L_{e q}$ can be calculated by:

$$
\begin{aligned}
& J \omega L_{P}+J \omega M I_{S_{2}}=V_{P_{1}} \\
& J \omega M I_{P_{1}}+\left(J \omega L_{s}+R_{L}\right) I_{S_{2}}=0
\end{aligned}
$$

Rearranging (11) and (12), we get (13):

$$
\frac{V_{P_{1}}}{I_{P_{1}}}=\frac{\omega^{2} M R_{L}}{R_{L}^{2}+\omega^{2} L_{S}^{2}}+J \omega\left(\frac{L_{P} R_{L}^{2}+\omega^{2} L_{S}\left(L_{P} L_{S}-M^{2}\right.}{R_{L}^{2}+\omega^{2} L_{S}^{2}}\right)
$$

On identifying the real and imaginary part in (13), the values of $R_{e q}$ and $L_{e q}$ can be found as:

$$
R_{e q}=\frac{\omega M R_{L}}{R_{L}^{2}+\omega^{2} L_{S}^{2}}
$$

$$
L_{e q}=L_{P}-\frac{\omega^{2} L_{S} M^{2}}{R_{L}^{2}+\omega^{2} L_{S}^{2}}
$$

The exact equivalent circuit of the $\mathrm{IH}$ system is shown in Figure 5 where $R e q$ and $L e q$ are connected in series. Additionally, a capacitor is connected in series to create the resonance condition shown in Figure 3.

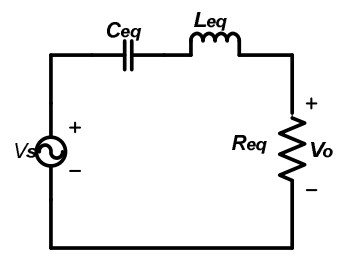

Fig. 5. The equivalent circuit of IH load/series RLC circuit

\section{B. Frequency Response Analysis of IH Load}

It is already mentioned that, $\mathrm{IH}$ load is modeled as a series connection of $R_{e q}, L_{e q}$, and $C_{e q}$. The voltage gain of the equivalent circuit shown in Figure 5 is used for frequency analysis. Here $V_{s}$ is the input voltage for the resonant tank and $V_{\text {out }}$ is the output voltage across resistance that has been taken for calculation of gain. The voltage gain equivalent circuit shown in Figure 5 can be defined as:

$$
G(S)=\frac{V_{o}(S)}{V_{i n}(S)}=\frac{R_{e q} I(S)}{I(S)\left(R_{e q}+S L_{e q}+\frac{1}{S C_{e q}}\right)}=\frac{R_{e q}}{R_{e q}+S L_{e q}+\frac{1}{S C_{e q}}}
$$

Putting $S=j \omega$ in (16):

$$
\begin{aligned}
\therefore G\left(j \omega_{s}\right)=\frac{V_{o}\left(j \omega_{s}\right)}{V_{i n}\left(j \omega_{s}\right)} & =\frac{R_{e q}}{R_{e q}+j \omega_{s} L_{e q}+\frac{1}{j \omega_{s} C_{e q}}} \\
& =\frac{1}{1+\frac{j \omega_{s} L_{e q}}{R_{e q}}-\frac{j}{\omega_{s} C_{e q} R_{e q}}}
\end{aligned}
$$

where $\omega_{s}$ is the switching frequency of the FBSRI. Resonant frequency and quality factor of series $R_{e q}, L_{e q}$ and $C_{e q}$ are defined as:

$$
\begin{aligned}
& \omega_{r}=\frac{1}{\sqrt{L_{e q} C_{e q}}}, Q=\frac{\omega_{r} L_{e q}}{R_{e q}} \\
& \therefore G\left(j \omega_{s}\right)=\frac{1}{1+j Q\left(\frac{\omega_{s}}{\omega_{r}}-\frac{\omega_{r}}{\omega_{s}}\right)}=\frac{1}{1+j Q\left(\mu-\frac{1}{\mu}\right)} \\
& \left|G\left(j \omega_{s}\right)\right|=\frac{1}{\sqrt{\left[1+Q^{2}\left(\mu-\frac{1}{\mu}\right)^{2}\right]}}
\end{aligned}
$$

where $\mu=\frac{\omega_{s}}{\omega_{r}}$. 
The magnitude plot for the different values of quality factor in (20) is shown in Figure 6. From Figure 6, it can be concluded that, as the quality factor increases, the selectivity for the resonant frequency increases, thereby maximizing power transfer occurs from source to load. It can be observed that maximum output power and maximum gain $G(j \omega)$ i.e. 1 could be obtained at the resonant frequency. By varying resonant frequency, the output power of FBSRI could be varied but it disturbs the quality factor of the resonant tank. So the characteristic of $R_{e q}, L_{e q}$, and $C_{e q}$ tank becomes selectively poor, thereby yielding poor regulation of the output power. Due to this, the switching frequency is kept fixed and near to resonant frequency. The switching frequency and quality factor for the FBSRI are calculated from (18).

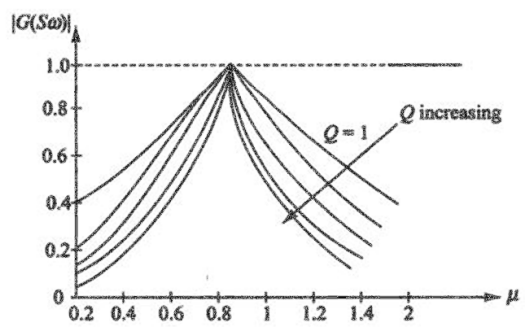

Fig. 6. Frequency response curve of $R_{e q}, L_{e q}$, and $C_{e q}$ series circuit

\section{SiMULATED MODEL AND RESULTS}

A $5 \mathrm{~kW}$ classical IH system based on the buck boost converter has been proposed and corroborated with PSIM. Design parameters and their values are given in Table I. Figure 7 shows the simulated model of the proposed classical IH system. In this work, a modified buck boost converter has been designed to control the output power of FBSRI. This modified buck boost converter has been designed to generate a regulated dc link output voltage $V_{B B}$ between $8 \mathrm{~V}$ and $124.71 \mathrm{~V}$ corresponding to duty cycle $0.2 \leq D \leq 0.8$. This variable $V_{B B}$ is fed to FBSRI. Thus, a wide range of values of the controlled output power across IH load is achieved through FBSRI.

TABLE I. DESIGNED PARAMETERS AND THEIR VALUES

\begin{tabular}{|c|c|}
\hline Designed Parameters & Values \\
\hline Input AC Voltage $\left(V_{r \cdot m . s}\right)$ & $230 \mathrm{~V}, 50 \mathrm{~Hz}$ \\
\hline Switching frequency $\left(f_{s}\right)$ for FB-SRI & $25 \mathrm{KHz}$ \\
\hline Filter inductance $\left(L_{f}\right)$ & $1 \mathrm{mH}$ \\
\hline Filter capacitance $\left(C_{f}\right)$ & $250 \mathrm{mF}$ \\
\hline Buck boost inductor $\left(L_{B B}\right)$ & $320.5 \mathrm{uH}$ \\
\hline Buck boost capacitor $\left(C_{B B}\right)$ & $2.49 \mathrm{mF}$ \\
\hline Resonating capacitor $\left(C_{e q}\right)$ & $0.8 \mathrm{uF}$ \\
\hline Equivalent inductance $\left(L_{e q}\right)$ & $52.7 \mathrm{uH}$ \\
\hline Equivalent resistance $\left(R_{e q}\right)$ & $5 \Omega$ \\
\hline HF Filter inductance $\left(L_{s}\right)$ & $25 \mathrm{uH}$ \\
\hline HF Filter capacitor $\left(C_{s}\right)$ & $5 \mathrm{uF}$ \\
\hline Maximum R.M.S output power $\left(P_{\text {out }}\right)$ & $5500 \mathrm{~W}$ \\
\hline
\end{tabular}

Figures $8(a)$ to $8(d)$ show the simulated waveforms of voltages and currents with regulated $V_{B B}$ at different duty cycles $D$ across $R_{e q}, L_{e q}$, and $C_{e q}$. Figures $8(\mathrm{a})$ and $8(\mathrm{~b})$ show the buck operating mode while Figures $8(\mathrm{c})$ and $8(\mathrm{~d})$ show the boost operating mode of the modified buck boost converter with the input of $30 \mathrm{~V}$ DC link voltage $\left(V_{d c l}\right)$. Thus, variable DC-link voltage $\left(V_{d c l}\right)$ has been obtained using modified buck boost converter. Non smoothing inductor $(L s)$ and capacitor $\left(C_{s}\right)$ have been used to mitigate HF component at the DC link voltage. The switching frequency for the buck boost converter has been kept at $30 \mathrm{KHz}$ along with the variable duty cycle but for FBSRI, switching frequency $f_{s}$ and duty cycle $\alpha$ of PWM have been kept at $25 \mathrm{kHz}$ and $50 \%$ respectively.

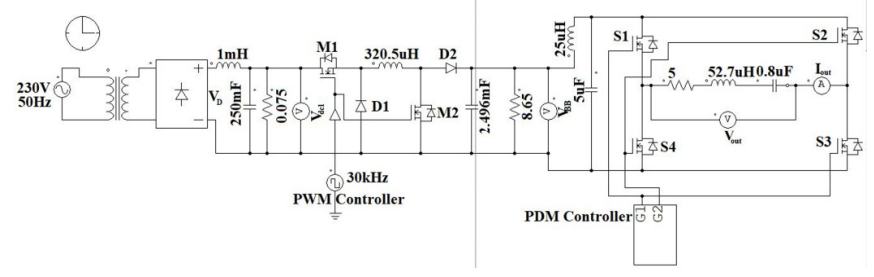

Fig. 7. Simulation model of the proposed classical IH system

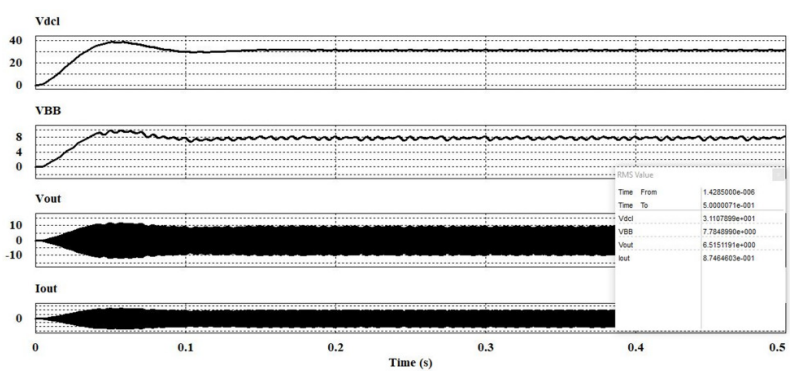

(a) At duty cycle $D=0.2$

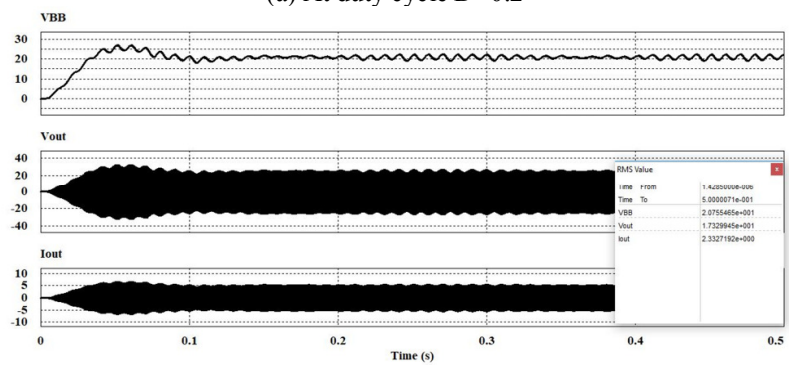

(b) At duty cycle $D=0.4$

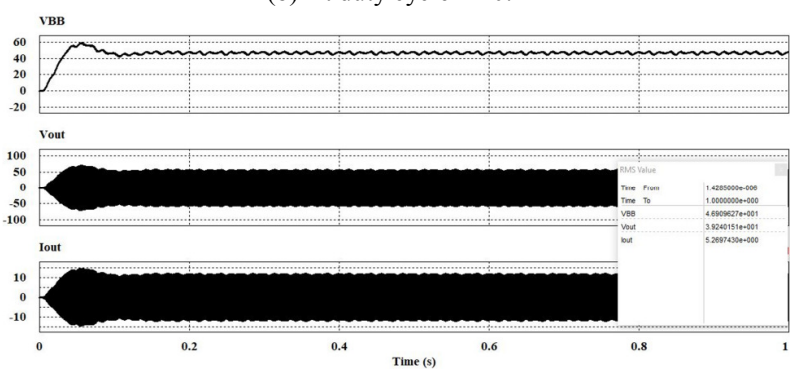

(c) At duty cycle $D=0.6$

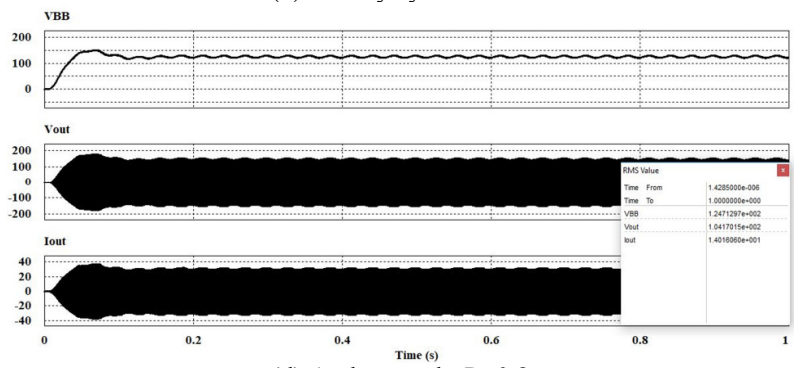

(d) At duty cycle $D=0.8$

Fig. 8. Simulated results across IH load at different duty cycles. 
FBSRI operates at the resonant frequency $f_{r}$ and is calculated by:

$$
\begin{aligned}
& \omega_{r}=\frac{1}{\sqrt{L_{e q} C_{e q}}} \\
& f_{r}=\frac{1}{2 \pi \sqrt{L_{e q} C_{e q}}}=\frac{1}{2 \pi \sqrt{52.7 \times 10^{-6} \times 0.8 \times 10^{-6}}} \approx 25 \mathrm{KHz}
\end{aligned}
$$

Pulse density modulation (PDM) controller has been used to generate pulses for the FBSRI as shown in Figures 9(a) and 9(b). Table II shows the variation of output power $P_{\text {out }}$ of the FBSRI with respect to variable duty cycle $\alpha$. Here, $\cos \theta$ (power factor) has been assumed as unity for the calculation of output power because the proposed FBSRI works on the resonant frequency. The graph between average output power $P_{\text {out }}$ versus duty cycle $\alpha$ is shown in Figure 10 which validates the linear relationship between $P_{\text {out }}$ and $\alpha$. From this figure, it can be concluded that as the duty cycle increases, output average power increases. Thus, simulation results show that the proposed IH system is more efficient and reliable.

TABLE II. OUTPUT POWER VS DUTY CYCLE

\begin{tabular}{|c|c|c|c|c|}
\hline$(\boldsymbol{\alpha})$ & $\mathbf{V}_{\mathbf{B B}}(\mathbf{V})$ & $\mathbf{V}_{\mathbf{o}}(\mathbf{V})$ & $\mathbf{I}_{\mathbf{o}}(\mathbf{A})$ & $\mathbf{P}_{\mathbf{o}(\mathbf{a v g})}=\mathbf{V}_{\mathbf{o}}{ }^{*} \mathbf{I}_{\mathbf{o}}(\mathbf{W})$ \\
\hline 0.2 & 7.82 & 6.54 & 0.88 & 5.75 \\
\hline 0.4 & 20.86 & 17.42 & 2.34 & 40.76 \\
\hline 0.6 & 46.90 & 39.24 & 5.27 & 206.79 \\
\hline 0.8 & 124.71 & 104.17 & 14.01 & 1459.42 \\
\hline
\end{tabular}

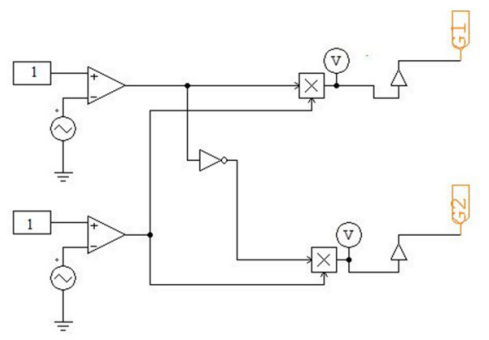

(a)

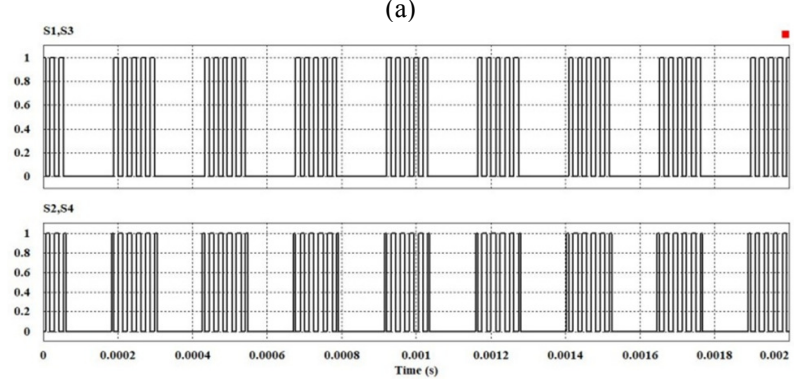

(b)

Fig. 9. (a) PDM controller and (b) its pulses

\section{CONCLUSIONS}

An efficient output power control technique has been implemented for the classical IH system which controls the DC link voltage and it has been verified in PSIM environment. The heating effect of this proposed IH system can be varied by using variable average output power of $5.5 \mathrm{~kW}$. Owing to this, whatever the requirements of power/heat, it can be regulated up to its rated power. This FBSRI transfers the maximum amount of current because it is resonating in nature. This DC link voltage control technique can be applied to both domestic and industrial induction heating (IH) applications.

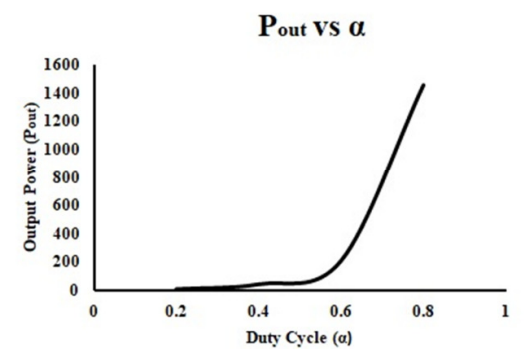

Fig. 10. Output power $\left(\mathrm{P}_{\text {out }}\right)$ vs duty cycle $(\alpha)$

\section{REFERENCES}

[1] O. Lucia, P. Maussion, E. J. Dede, J. M. Burdio, "Induction Heating Technology and its Applications: Past Developments, Current Technology, and Future Challenges", IEEE Transactions on Industrial Electronics, Vol. 61, No. 5, pp. 2509-2520, 2014

[2] A. Kumar, M. Sadhu, N. Das, P. K. Sadhu, D. Roy, A. Ganguly, “A Survey on High-Frequency Inverter and Their Power Control Techniques for Induction Heating Applications", Journal of Power Technologies, Vol. 97, No. 3, pp. 201-213, 2017

[3] S. Lupi, "Survey on Induction Heating Development in Italy", Third IEEE History of Electro-Technology Conference, Pavia, Italy, September 5-7, 2012

[4] A. Dominguez, L. A. Barrangan, J. I. Artigas, A. Otin, I. Urriza, D. Navarro, "Reduced-Order Models of Series Resonant Inverters in Induction Heating Applications", IEEE Transactions on Power Electronics, Vol. 32, No. 3, pp. 2300-2311, 2017

[5] N. Yongyuth, P. Viriya, K. Matsuse, "Analysis of a Full-Bridge Inverter for Induction Heating Using Asymmetrical Phase-Shift Control under ZVS and NON-ZVS Operation", 7th International Conference on Power Electronics and Drive Systems, Bangkok, Thailand, November 27-30, 2007

[6] H. Sarnago, O. Lucia, A. Mediano, J. M. Burdio, "Analytical model of the half-bridge series resonant inverter for improved power conversion efficiency and performance", IEEE Transactions on Power Electronics, Vol. 30, No. 8, pp. 4128-4143, 2015

[7] A. Shenkman, B. Axelrod, Y. Berkovich, "Improved modification of the single-switch AC-AC converter for induction heating applications", IEE Proceedings-Electric Power Applications, Vol. 151, No. 1, pp. 1-4, 2004

[8] C. M. Wang, H. J. Chiu, D. R. Chen, "Novel zero-current-switching (ZCS) PWM converters", IEE Proceedings-Electric Power Applications, Vol. 152, No. 2, pp. 407-415, 2005

[9] F. Forest, S. Faucher, J. Y. Gaspard, D. Montloup, J. J. Huselstien, C. Joubert, "Frequency-synchronized resonant converters for the supply of multiwinding coils in induction cooking appliances", IEEE Transactions on Industrial Electronics, Vol. 54, No. 1, pp. 441-452, 2007

[10] C. Carratero, O. Lucia, J. Acero, J. M. Burdio, "Phase-shift control of dual half-bridge inverter feeding coupled loads for induction heating purposes”, Electronics Letters, Vol. 47, No. 11, pp. 670-671, 2011

[11] V. Esteve, E. S. Kilders, J. Jordan, E. J. Dede, C. Cases, E. Maset, J. B. Ejea, A. Ferreres, "Improving the efficiency of IGBT series-resonant inverters using pulse density modulation", IEEE Transactions on Industrial Electronics, Vol. 58, No. 3, pp. 979-987, 2011

[12] B. Meziane, H. Zeroug, "Comprehensive power control performance investigations of resonant inverter for induction heating surface hardening", IEEE Transactions on Industrial Electronics, Vol. 63, No. 11, pp. 6086-6096, 2016

[13] H. Sarnago, O. Lucia, A. Mediano, J. M. Burdio, "Class D/DE dualmode-operation resonant converter for improved-efficiency domestic induction heating system", IEEE Transaction on Power Electronics, Vol. 28 , No. 3, pp. 1274-1285, 2013 
[14] J. Acero, C. Carretero, R. Alonso, J. M. Burdio, "Quantitative evaluation of induction efficiency in domestic induction heating applications", IEEE Transactions on Magnetics, Vol. 49, No. 4, pp. 1382-1389, 2013

[15] C. Carretero, O. Lucia, J. Acero, R. Alonso, J. M Burdio, "Frequencydependent modelling of domestic induction heating using numerical methods for accurate time-domain simulation", IET Power Electronics, Vol. 5, No. 8, pp. 1291-1297, 2012

[16] V. Esteve, J. Jordan, E. S. Kilders, E. J. Dede, E. Maset, J. B. Ejea, A. Ferreres, "Enhanced pulse density modulated power control for high frequency induction heating inverters", IEEE Transactions on Industrial Electronics, Vol. 62, No. 11, pp. 6905-6914, 2015

[17] V. Esteve, J. Jordan, E. S. Kilders, E. J. Dede, E. Maset, J. B. Ejea, A. Ferreres, "Improving the reliability of series resonant inverters for induction heating applications", IEEE Transactions on Industrial Electronics, Vol. 61, No. 5, pp. 2564-2572, 2014

[18] O. Fernandez, J. Delgado, F. Martinez, J. Correa, M. Heras, "Design and implementation of a 120 A resonant inverter for induction furnace", IEEE International Autumn Meeting on Power, Electronics, and Computing, Mexico City, Mexico, November 13-15, 2013

[19] N. A. Ahmed, "High-frequency soft-switching AC conversion circuit with dual PWM/PDM control strategies for high-power IH applications", IEEE Transactions on Industrial Electronics, Vol. 58, No. 4, pp. 1440-1448, 2011

[20] B. Patidar, M. M. Hussain, S. K. Jha, B. Dikshit, A. Sharma, "Modelling and experimental demonstration of a litz coil-based high-temperature induction heating system for melting application", IET Electric Power Applications, Vol. 12, No. 2, pp. 161-168, 2018

\section{AUTHORS PROFILE}

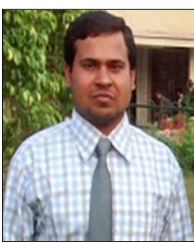

Anand Kumar was born in Bokaro, Jharkhand, India in 1991. He received his B.E degree in Electrical and Electronics Engineering from the Rajiv Gandhi Technological University, Bhopal, Madhya Pradesh, India in 2012 and M.E degree in Power Electronics (Electrical Engineering) from Birla Institute of Technology, Mesra, Ranchi, India in 2014. He served as an Assistant Professor in Department of Electrical Engineering at Guru Gobind Singh Educational Society Technical Campus (GGSESTC), Kandra, Bokaro, India. He is presently pursuing Ph.D in Department of Electrical Engineering at Indian Institute of Technology (Indian School of Mines), Dhanbad, India. His Research Interest includes Power Electronics converters, High Frequency Resonant Converter, Direct AC-AC converters, applications of Resonant Converter in Domestic as well as Industrial Induction Heating systems. At present he is engaged in research work on "Analysis and Power Control technique in High Frequency Inverter in Induction Heating System".

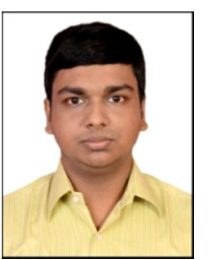

Debayan Sarkar was born in Kharagpur, West Bengal, India in 1992. He received his B.Tech degree in Electrical Engineering \& M.Tech degree in Power Systems from Department of Electrical Engineering, National Institute of Technology, Durgapur, India in the year 2015 \& 2017 respectively. Presently, he is pursuing his $\mathrm{Ph} . \mathrm{D}$ under the guidance of Prof. P. K. Sadhu, Department of Electrical Engineering, Indian Institute of Technology (Indian School of Mines), Dhanbad, India. His research interests include maximum power extraction from BIPV and roof integrated PV systems, solar photovoltaic power generation techniques, DC-DC power electronics converter topologies, IoT in electrical engineering applications, monitoring and analysis of dielectric strength of transformer oil \& High Voltage Engineering. Presently, he is engaged in a research work entitled, "Maximum Power Extraction Approach from Building Integrated Photovoltaic's (BIPV)".

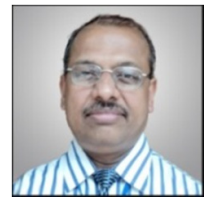

Pradip Kumar Sadhu received his B.E., M.E. and Ph.D. (Engineering) degrees in Electrical Engineering from Jadavpur University, West Bengal, India. $\mathrm{He}$ is presently working as a Professor and as the Head of the Department of Electrical Engineering of the Indian Institute of Technology (Indian School of Mines), Dhanbad, India. $\mathrm{He}$ has a total of 30 years of experience including 18 years of teaching and research plus 12 years in the industry. He has four granted patents and twenty seven patents that are under process. He has several journal and conference publications at national and international levels. $\mathrm{He}$ is the principal investigator of few government funded projects. His current research interest includes power electronics applications, the application of high frequency converters, energy efficient devices, energy efficient drives, computer aided power system analysis, condition monitoring, lighting and communication systems for underground coal mines. 